of iodoform in pills containing each one centigramme $\left(\frac{1}{6} \mathrm{gr}\right)$. She was suddenly attacked with faintness, vertigo, and double vision; within two days she sank into a deep sleep which lasted for thirty-six hours, and was followed by excitement, violent headache, and confused speech. These symptoms were succeeded by debility and a tottering gait, after which the vertigo, headlache and diplopia recurred. This series of symptoms lasted for a fortnight. In the case of another woman, the toxical phenomena occurred at the end of the first week, and when no more than 5 grammes ( $75 \mathrm{grs}$.) of iodoform had been taken. She slept continuously for five days, after which debility and vertigo were experienced for several weeks. (Oberlander)."

In my own experience, I have observed no such phenomena from the use of iodoform internally. But in every case in which I have employed it as an internal remedy, the combination with nux vomica, digitalis, and ext. belladonna overcomes or prevents its depressing influence upon the circulation and respiration; and as these remedies are cardiac and respiratory tonics, I think it a most rational method of obviating the dangerous effects sometimes resulting from the internal use of iodoform.

Chicago Opera House Bulding.

\section{FRACTURE OF THE RIB CAUSED BY SNEEZING.}

\section{BY HAL. C. WYMAN, M.D.}

SURGKON TO THE, WEST ENIS MISIENSARY, DETROIT, MICH.

There is a Hebrew legend which says that before the days of Jacob no man sneezed more than oncethe effort cost him his life. Jacob invoked the blessing of God and survived an attack, and since his time it has been customary for persons, in the presence of one sneexing, to utter a "Praise God!" "Gesundheit!" or other significant exclamation, lest the phenomenon result fatally. That sneezing may not, in all cases, be the harmless action it is commonly believed to be, the following case will serve to illustrate:

Mr. M., aged 72 years, remarkably vigorous and healthy for his years, summoned me hastily for relief of severe pain in his right side, which had commenced suddenly after sneezing with unusual force. I found him standing, supported by a chair; his face pale, his breathing difficult and provoking cries, with pain in the lower part of the right side. I suspected.pleuritis and neuralgia; and was surprised on placing my ear on his chest to hear distinctly the crepitus peculiar to fracture of bone. Further examination showed a fracture of the eighth rib, near its angle. The treatment consisted in placing three strips, fourteen inches in length, of Seabury \& Johnson's rubber adhesive plaster obliquely over the right side, crossing the ribs at right angles. The plasters were adjusted with sufficient firmness to draw the ribs snugly together, and to limit the motion of the fractured one. Recovery was prompt and without complication.

This case is of interest, because it was unquestionably caused by sneezing, and the fact that sneezing is not usually referred to as a cause of fracture of the ribs. A glance at the mechanics of sneezing will show that two powerful sets of muscles may be brought into antagonism in a way to expend their opposed forces upon the ribs, making the fracture simply a mechanical matter.

The treatment by means of plasters having some permanency of adhesive power has proven in many cases of fractured ribs, as it did in this one, a great advantage over the old method of a broad bandage encircling the chest. It permits freedom of motion on the uninjured side of the chest, while it insures sufficient immobilization of the fractured bone to control pain and favor union.

It is said that insane persons are particularly prone to tracture of the ribs, and that sneezing among them is not infrequently the cause. Whether there is, in these cases, a dominant frailty of rib-structure, or an unusual quantity of muscular force called out by the mental unsoundness and applied to the ribs in the act of sneezing, is an interesting point to determine.

\section{OPERATION FOR MALFORMED AURICLE.'}

$$
\text { BY S. S. BISHOP, M.D., }
$$

SURGEON TO THE ILIANOIS CHARITABIEE HF AND EAR INFIRMARY AND SOLTH SIDE FREE DISFlESARI.

On July I Ith, I $88_{5}$, Nettie H., eight years old, presented herself at my clinic at the Infirmary and said she "wanted her ears put back." Both auricles were so abnormally prominent as to mar materially the symmetry of a very shapely face and head. 'The left auricle, which was the more unsightly, projected one and one-fourth inches at a right angle from the junction of the auricle with the mastoid process, and then bent forwards; thus forming what is facetiously termed "lop-ear," or "dog-ear." The natural elevations and depressions were obliterated, and the organ presented the appearance of having been flattened by the pressure of the head in sleep on an auricle folded forward upon itself. The right ear projected one inch, but was not as imperfectly shaped as the left one. At first I contemplated moulding the auricle into shape in a dressing of plaster of Paris, which would retain the parts in position for several months, with proper care and renewed dressings. But on account of the youthfulness of the child, which would render it highly improbable that she would cooperate in that treatment with sufficient persistence to insure success, I performed an operation, with the consent of her parents, and with the assistance of Drs. Hawley, Abbott and Walker.

On July I 7 th the little patient was anæsthetized with ether. An incision one and three-fourths inches long was made on the posterior surface of the auricle about one-half inch from the free border of the cartilage, and parallel therewith. Another curvilinear incision internal to the first was made, to unite its extremities. These incisions extended only through the skin and subcutaneous tissue, and were made to embrace about one-half inch of integument at the widest divergence of the lines of incision. After dissecting off this skin and subcutaneous tissue, two incisions parallel to the first were made through

IRead before the Chicago Society of Ophthalmology and Otology, August II, 1885 . 